\title{
Gender Predilection and Confounding Factors Affecting Pre Hospital Delay Among Acute Myocardial Infraction Patients.
}

\author{
Jayesh Sharma ${ }^{1}$, Avanish kumar Bhardwaj ${ }^{1}$ \\ ${ }^{1}$ DM Final Year Cardiology, Department of Cardiology, S.P. Medical College, Bikaner.
}

\section{Abstract}

Background: Acute Myocardial Infarction (AMI) is a serious and life-threatening manifestation of coronary artery disease (CAD) affecting both males and females, which need immediate management. The present study was aimed to assess the gender difference and factors affecting pre-hospital delay among patients with AMI. Subjects and Methods: The 291 patients admitted with AMI from01-01-2018 to 3112-2018 were studied. A descriptive comparative design was adopted for the study. Socio personal and clinical variables of the subjects were assessed. Pre-hospital delay was measured in terms of time from the onset of symptoms till the patient reaches a health care setting. One hour after the onset of symptom of AMI was considered as the Golden hour. Data was analyzed using SPSS 20.0 software. Results: Out of the 291 patients with AMI (146 males and 145 females), only 32.4\% of males and $24.1 \%$ of females reached a health care setting within 1 hr of onset of symptoms. $35.2 \%$ of male patients and $43.5 \%$ of female patients reached the health care setting only after 6 hrs of onset of symptoms. Among the male patients, pre hospital delay was significantly associated with place of onset of symptoms ( $\mathrm{p}<0.05)$, presence of someone with the patient at the time of onset of symptoms $(\mathrm{p}<0.05)$, and perception of symptoms developed, as an emergency $(\mathrm{P}<0.001)$. Whereas in female patients, significant association was observed in pre hospital delay with age of the patient $(\mathrm{p}<0.05)$, nature of the first symptom experienced $(\mathrm{P}<0.05)$ and perception of symptoms developed as an emergency $(\mathrm{p}<0.001)$. Conclusion: Our study shows the existence of pre hospital delay among patients with AMI in both males and females. The factors affecting pre hospital delay vary between males \& females.

Keywords: Pre hospital Delay, Acute Myocardial Infarction.

Corresponding Author: Dr. Avanish kumar Bhardwaj, DM Final Year Cardiology, Department of Cardiology, S.P. Medical College, Bikaner. Email: drjitendraacharya@yahoo.in

Received: March 2020

Accepted: March 2020

\section{Introduction}

Being a life-threatening manifestation of CAD, AMI needs prompt recognition and management. Despite major advance in technology resulting in innovative reperfusion therapies, majority of individuals with AMI symptoms do not seek professional medical treatment in a timely manner. This treatment seeking delay contributes significantly to the disability \& death associated with AMI. AHA guidelines recommend appropriate medical interventions to be administered within one hour of onset of symptoms ("golden hour") for maximum reperfusion and to minimize damage of myocardial tissue. ${ }^{[1]}$

Many a time's patients take more than one hour to decide to seek treatment. Those patients who used emergency medical service had significantly shorter pre-hospital delay time than those who transported themselves to the hospital. ${ }^{[2]}$

Comparison of pre hospital behavior patterns of men \& women following acute onset of chest pain revealed that severity of symptoms proved to be the strongest influence in shortening pre-hospital delay. Men were more ready than woman to believe that they might be having a heart attack $\&$ this belief led them to seek treatment promptly. ${ }^{[3]}$

Pre-hospital delay is affected by age of the patient, severity of angina pain, history of CAD and perception of symptom as a cardiac problem. ${ }^{[4]}$ Variables that significantly predict pre-hospital delay are Misinterpretation of nature of pain, illiteracy and pain resistance behavior. Interventions to decrease pre-hospital delay must focus on improving public awareness of AMI symptoms and early treatment benefits. ${ }^{[5]}$ In this study, we aim to study gender difference and factors affecting pre-hospital delay in patients admitted at Haldi Ram moolchand heart hospital S.P. Medical College Bikaner Rajasthan.

\section{Subjects and Methods}

A descriptive comparative study was conducted in the department of cardiology, Sp Medical College, BIKANER among patients admitted with AMI from 01-01-18 to 31-1218.

\section{Inclusion Criteria}

Patients with AMI who are hemodynamic ally stable at the time of data collection were included in the study.

\section{Exclusion Criteria}

Patients who are mentally challenged where excluded.

A total 291 patients with AMI (146 males and 145 females) were enrolled in the study. After explaining the purpose of the study and ensuring confidentiality of the data informed 
written consent was obtained. Data were collected using semi structured interview schedule to assess factors affecting pre-hospital delay. Data were analyzed using 20th version of SPSS statistical package. Pre hospital delay was categorized as <1hr, 2-6 hrs, >6 hrs. The gender difference in pre-hospital delay between males \& females were analyzed. Association of pre-hospital delay and factors affecting delay was computed among both males \& females.

\section{Results}

A total of 291 patients diagnosed with AMI were studied. Among the participants $77.6 \%$ belonged to the age group 51-70 yrs. All the studied patients were residing in an area at distance of $<10 \mathrm{~km}$ from Govt. Medical College Hospital Bikaner. $90.7 \%$ of the participants were unaware of the emergency ambulance number. $44.5 \%$ of them used auto rickshaw as a mode of transportation to hospital. $46.6 \%$ of participants were diabetic and $42.8 \%$ of them had previous history of AMI. $64.8 \%$ of the participants were unaware of symptoms of AMI. 52\% of the patients reported chest pain as the first symptom experienced first symptom to experience.

Among the total 291 patients only $28.3 \%$ reached the hospital within the golden hour (1 hour) after MI. 32.4\% reached with 1-6 hrs and 39.3\% reached only after $6 \mathrm{hrs}$ of onset of symptoms. There was no statistically significant association between pre-hospital delay and gender ( $p$ $>0.05$ ). Male patients who developed the symptoms at their work place, perceived the symptom as an emergency and those who had someone with them during the onset of symptom had significantly shorter pre-hospital delay ( $p$ $<0.05)$. Whereas among female patients who experienced chest pain as the first symptom and perceived the symptom as an emergency had significantly shorter pre-hospital delay $(\mathrm{p}<0.05, \mathrm{p}<0.001)$.

\section{Table 1: Age Wise Distriution}

\begin{tabular}{|l|l|l|}
\hline Age (Years) & F & \% \\
\hline $31-40$ & 11 & 3.8 \\
\hline $41-50$ & 54 & 18.6 \\
\hline $51-60$ & 92 & 31.4 \\
\hline$>60$ & 134 & 46.2 \\
\hline
\end{tabular}

Table 2: Distances Between Residence And Nearest Hospital (KM)

\begin{tabular}{|l|l|l|}
\hline $0.5-2.5$ & 156 & 53.5 \\
\hline $2.5-6$ & 89 & 30.7 \\
\hline $6-10$ & 46 & 15.8 \\
\hline
\end{tabular}

Table 3: Place of onset of Symptoms

\begin{tabular}{|l|l|l|}
\hline House & 231 & 79.3 \\
\hline Work place & 38 & 13.1 \\
\hline Travel & 19 & 6.6 \\
\hline Others & 3 & 1 \\
\hline
\end{tabular}

Table 4: Pre Hospital Delay (In Hrs)

\begin{tabular}{|l|l|l|}
\hline 1 & 83 & 28.3 \\
\hline $1-6$ & 94 & 32.4 \\
\hline$>6$ & 114 & 39.3 \\
\hline
\end{tabular}

\section{Discussion}

In the present study $96.2 \%$ of the participants were aged above $40 \mathrm{yrs}$. This finding is in concordance with the findings of the study conducted to forecast the prevalence of rates of $\mathrm{CHD}$ and the study conducted at SRG Hospital Thalawar to determine risk factors of AMI both of which revealed that prevalence rates of CHD among adults aged $40 \mathrm{yrs}$. and above are likely to increase. ${ }^{[6,7]}$

In our study $46.6 \%$ of the participants were diabetic which is found matching with the prospective case control study from intensive care unit to assess the risk factors for AMI in coastal region of India. The study concluded that DM is an independent risk factor for AMI. ${ }^{[8]}$

Among the participants, $71.7 \%$ of them reached the healthcare setting after the Golden hour of AMI (i.e. $1 \mathrm{hr}$ after the symptom onset). A study conducted by Indian College of cardiology Kerala state Registry also showed that $88 \%$ of the patients with AMI reached the health care facility after one hour of onset of symptoms. ${ }^{[9]}$

The present study showed that $32.4 \%$ of males with AMI reached the health care setting within one hour whereas only $24.1 \%$ females reached within one hour. This finding was found similar to a number of studies which concluded that female have a greater prehospital delay than males. ${ }^{[10]}$ Present study revealed no statistically significant association between pre-hospital delay and gender. This finding was supported by the studies conducted by University hospital Salvador and Andhra Medical College, Vishakhapatnam which showed that gender did not change the association of interest. ${ }^{[1]}$

Females above 60 yrs. of age had a comparatively prolonged pre-hospital delay in the present study which is in concordance with the findings of the study conducted to assess factors associated with pre-hospital delay which showed an increase in pre hospital delay with older age. ${ }^{[12]}$ A study conducted to compare North American and Australian patient's sociodemographic, clinical, cognitive, emotional and social factors associated with behaviour in seeking treatment for symptoms of MI showed that patients who were at home during onset of symptoms had a longer pre-hospital delay. The present study also showed a longer pre-hospital delay among male patients who were at home during onset of symptoms of AMI. ${ }^{[13]}$

Present study revealed that, among the participants who perceived the symptoms of AMI as an emergency majority of them reached a health care setting within one hour of onset of symptoms. A cross sectional survey conducted at CCU of Dr. Heshmat Hospital Rasht also showed that perceiving the symptoms of AMI as not so serious was a factor causing longer pre-hospital delay. ${ }^{[14]}$

Present study concluded that there was no significant association between pre-hospital delay and literacy, mode of transportation and previous history of AMI. This is in concordance with the findings of a study conducted at Andhra Medical College which also showed that there was no significant association between pre-hospital delay and age, literacy, mode of transportation and previous history of 
AMI.

\section{Conclusion}

AMI is a medical emergency requiring immediate management to save the life of the victims. Many of the patients with AMI were unaware of the symptoms and were unable to reach \& health care setting within the golden hour after MI. Moreover, majority of them don't even know the emergency ambulance number. Enhanced public awareness is the need of the time to reduce the morbidity and mortality from AMI.

\section{References}

1. Roger VL, Go AS, Lloyd-Jones DM, et al. Heart disease and stroke statistics--2012 update: a report from the American Heart Association. Circulation 2012;125(1):e2-e220.

2. Wang X, Hsu LL. Treatment-seeking delays in patients with acute myocardial infarction and use of the emergency medical service. Journal of International Medical Research 2013;41(1):231-223.

3. Foster S, Mallik M. A comparative study of differences in the referral behaviour patterns of men and women who have experienced cardiacrelated chest pain. Intensive Crit Care Nurs 1998;14(4):192-202.

4. Alavi N, Dianati M, Hajibagheri A, et al. The pre-hospital delay in seeking treatment in patients with acute myocardial infarction referring to a central hospital in Kashan, Iran. Indian J Med Sci 2010;64(10):448-454.
5. Ghazawy ER, Seedhom AE, Mahfouz EM. Predictors of delay in seeking health care among myocardial infarction patients, Minia District, Egypt. Advances in Preventive Medicine 2015;2015:1-6.

6. Chauhan S, Aeri BT. Prevalence of cardiovascular disease in India and its economic impact -a review. International Journal of Scientific and Research Publications. 2013;3(10):1-5.

7. Pandey S, Pandey S, Jhanwar P, et al. A prospective study of Myocardial Infarction patients admitted in a tertiary care hospital of south-eastern Rajasthan. Int J Biol Med Res 2012;3(2):1694-1696.

8. Rao V, Rao P, Carvalho N. Risk factors for acute myocardial infarction in coastal region of India: a case-control study. Heart India 2014;2(3):70-75

9. Reporter S. Give prompt treatment for patients with chest pain. The Hindu 2015. Available from http://www.thehindu.com/ news/cities/ Kochi/give- prompt-treatment-for-patients-with-chest-pain/ article7691306. ece

10. Bouma J, Broer J, Bleeker J, et al. Longer pre-hospital delay in acute myocardial infarction in women because of longer doctor decision time. J Epidemiol Community Health 1999;53(8):459-464.

11. Momeni M, Salari A, Ghanbari A, et al. Sex differences in duration of pre-hospital delay in patients with acute myocardial infarction. Journal of PayavardSalamat 2013;7(2):133-142.

12. Sari I, Acar Z, Ozer O, et al. Factors associated with prolonged prehospital delay in patients with acute myocardial infarction. Turk KardiyolDernArs - Arch Turk SocCardiol 2008;36(3):156-162.

13. McKinley S, Moser DK, Dracup K. Treatment-seeking behavior for acute myocardial infarction symptoms in North America and Australia. Heart Lung 2000;29(4):237-247.

14. Momeni M, Salari A, Shafighnia S, et al. Factors influencing prehospital delay among patients with acute myocardial infarction in Iran. Chin Med J 2012;125(19):3404-3409.

Copyright: (C) the author(s), 2020. It is an open-access article distributed under the terms of the Creative Commons Attribution License (CC BY 4.0), which permits authors to retain ownership of the copyright for their content, and allow anyone to download, reuse, reprint, modify, distribute and/or copy the content as long as the original authors and source are cited.

How to cite this article: Sharma J, Bhardwaj AK. Gender Predliction and Confunding Factors Affecting Pre Hospital Delay Among Acute Myocardial Infraction Patients. Asian J. Med. Res. 2020;9(1):ME10-ME12.

DOI: dx.doi.org/10.47009/ajmr.2020.9.1.ME3

Source of Support: Nil, Conflict of Interest: None declared. 